\title{
DFT study of carbon dioxide capture on functionalized graphane sheets
}

\author{
Yanjun Xiao, Zhigang Deng and Chi-Man Lawrence Wu
}

\begin{abstract}
CO}_{2}$ capture and storage is a potential means to alleviate global warming and ocean acidification. Herein, $\mathrm{CO}_{2}$ capture with various functionalized graphanes and the effects of functional groups are investigated by density functional theory (DFT). Our results show that $\mathrm{CO}_{2}$ adsorbs weakly on a bare graphane sheet, and absorbs slightly better when functionalized with P-substituted graphane, and increasingly better with $\mathrm{PH}_{2}$-grafted on $\mathrm{H}$ atoms. Further, the presence of $\mathrm{H}_{2} \mathrm{O}$ would provide strong $\mathrm{CO}_{2}$ adsorption and the exothermic adsorption energies could reach about $-42 \mathrm{~kJ} / \mathrm{mol}$ with $\mathbf{P H}_{2}-$ grafted on graphane. This computational work provides an atomic-level strategy in the design of functionalized graphane and carbon-based adsorbent materials for $\mathrm{CO}_{2}$ capture and storage.
\end{abstract}

Keywords-DFT, $\mathrm{CO}_{2}$ capture, Graphane, Functional groups

\section{Introduction}

The concentration of greenhouse gas carbon dioxide $\left(\mathrm{CO}_{2}\right)$ in the atmosphere has risen from about 310 to 390 ppm over the past few decades, and the $\mathrm{pH}$ value of surface seawater would decrease from 8.2 to 7.8 by 2095 for the accumulation effect of dissolved $\mathrm{CO}_{2} \cdot{ }^{[1]}$ Carbon capture and storage (CCS) is a promising approach to capture waste $\mathrm{CO}_{2}$ from large point sources, such as fossil fuel power plants, and has attracted considerable attention during the past several years. CCS transports $\mathrm{CO}_{2}$ to a storage site, or deposits it to, for example, an underground geological formation to avoid it entering the atmosphere. ${ }^{[2]} \mathrm{CO}_{2}$ capture and separation at stationary point source is very important for practical CCS applications. ${ }^{[3]}$ So, one of the key issues to improve $\mathrm{CO}_{2}$ capture performance is to explore efficient capture materials, which should have high $\mathrm{CO}_{2}$ adsorption capacity, excellent adsorption selectivity, and good chemical and mechanical stability. ${ }^{[4]}$ Various adsorbent materials have been proposed for $\mathrm{CO}_{2}$ capture. They include carbon nanotubes, ${ }^{[5-8]}$ activated carbon, ${ }^{[9]}$ porous organic polymers, ${ }^{10,11]}$ covalent organic frameworks, ${ }^{[12,13]}$ metal organic frameworks, ${ }^{[14]}$ nanoporous carbons, ${ }^{[15]}$ porous graphane membranes, ${ }^{[16]}$ and Zeolites. ${ }^{[17,18]}$ However, due to their physical characteristics or economic consideration in the processes of synthesis, manufacture and regeneration, they are not fully desirable. Therefore, the development of feasible materials to enhance $\mathrm{CO}_{2}$ capture and separation is still outstanding.

Yanjun Xiao, Zhigang Deng and Chi-Man Lawrence Wu Dept. of Physics and Materials Science, City University of Hong Kong P.R. China
Graphane, a lengthened two-dimensional (2-D) polymer of hydrocarbon, is a burgeoning carbon-based material with attractive properties. ${ }^{[19]}$ Graphane is composed of a monolayer of 2-D sheets of carbon atoms, and the carbon bonds of graphane are in $\mathrm{sp}^{3}$ configuration, as opposed to graphene's $\mathrm{sp}^{2}$ bond configuration. ${ }^{[20,21]}$ Unlike graphene, hydrogen grafted to a carbon atom on graphane sheet can be substituted by functionalities without affecting the remaining parts of the graphane structure. ${ }^{[22]}$ Maximized atomic utilization and tunable composition and functionalities of graphane ${ }^{[23,24]}$ offer new possibilities for structure of materials based on two-dimensional carbon for applications including adsorption and catalysis. Xiao et $a l .{ }^{[22]}$ investigated $\mathrm{CO}_{2}$ adsorption thermodynamics over Nsubstituted/grafted graphanes using DFT. As Phosphorus is a congener of nitrogen, and P-doped graphane is postulated to be a high-temperature superconductor with a $T_{c}$ above 90 $\mathrm{K}$, based on the BCS theory, ${ }^{[25]}$ this material is thought to have special absorption properties. However, P-doped graphane as adsorbent material has not been investigated.

In this paper, we present a DFT investigation of $\mathrm{CO}_{2}$ adsorption over P-substituted/grafted graphanes. $\mathrm{CO}_{2}$ adsorption energies over graphanes with or without $\mathrm{P}$ functionalization are compared to identify the effects of Psite density and position. The effect of moisture addition is also explored. The partial density of states (PDOS) analysis is preformed to elucidate the $\mathrm{CO}_{2}$ adsorption rule. This work therefore contributes to the fundamental understanding of the structural, energetic, and electric properties of substituted/grafted graphanes for $\mathrm{CO}_{2}$ adsorption and may be useful for the design and screening of adsorbent materials for carbon capture and storage.

\section{Computational details}

DFT calculations were performed with the $\mathrm{DMol}^{3}$ program package in Materials Studio 7.0 of Accelrys Inc., using the exchange-correlation functional of GGA-PW91 approximation. A vacuum layer of $15 \AA$ was added perpendicular to the single layer surface. A $(3 \times 3 \times 1)$ Monkhorst-Pack (MP) ${ }^{[26]} k$-point mesh was used for all of the surfaces. The system was modeled as a $4 \times 4$ supercell of graphane, which contained $32 \mathrm{C}$ atoms plus $32 \mathrm{H}$ atoms, as shown in Fig. 3.1a. The unit cell of graphane was initially optimized as $\mathrm{a}=\mathrm{b}=2.46 \AA$, which is close to the reported unit cell values of graphane $(a=b=2.52 \AA) .{ }^{[21]}$ The atomistic models of graphane was built as chair conformation as it is more stable than the boat configuration. ${ }^{[21]}$ The isolated gas phase adsorbates $\left(\mathrm{CO}_{2}\right.$ and $\mathrm{H}_{2} \mathrm{O}$ ) were optimized separately. All the atoms in the cell were relaxed and all calculations were spin-polarized.

The adsorption energy $\left(E_{a}\right)$ is calculated by subtracting the sum of the energy of the isolated adsorbent surface and the energy of the optimized gas-phase adsorbate from the energy of the optimized adsorbate-adsorbent system, which can be expressed by the following equations: 


$$
E_{a}=E_{\text {adsorbent-adsorbent }}-E_{\text {adsorbent }}-E_{\text {gas }}
$$

where $E_{\text {adsorbent }}$ is the energy of the bare or functionalized graphane adsorbent, $E_{\text {gas }}$ is the energy of isolated $\mathrm{CO}_{2}$ or $\mathrm{H}_{2} \mathrm{O}, \quad E_{\text {adsorbent-adsorbent }}$ is the total energy of the adsorbent-adsorbent system, such as the adsorbent- $\mathrm{CO}_{2}$, the adsorbent $-\mathrm{H}_{2} \mathrm{O}$, and the adsorbent- $-\left(\mathrm{CO}_{2}+\mathrm{H}_{2} \mathrm{O}\right)$ system. A more negative $E_{\mathrm{a}}$ indicates a stronger adsorption.

\section{Results and discussion}

\section{A. $\mathrm{CO}_{2}$ adsorption over P-Substituted and $\mathrm{PH}_{2}$-grafted graphanes}

The optimized basic graphane surfaces (a) bare, (b) Psubstituted, and (c) $\mathrm{PH}_{2}$-grafted are shown in Fig. 1. The substitution of a single $\mathrm{C}$ atom in the lattice with a $\mathrm{P}$ atom led to P concentration of 3.13 wt \%. As shown in Fig. 1a, the bare graphane structure is in a chairlike conformation with the $\mathrm{H}$ atoms alternating on both sides of the plane, which is a preferable conformation compared to the boatlike conformer with the $\mathrm{H}$ atoms alternating in pairs. ${ }^{[21,22]}$ All the $\mathrm{C}$ atoms form a hexagonal network, and the calculated $\mathrm{C}-\mathrm{C}$ bond length is $1.50 \AA$, similar to the $\mathrm{sp}^{3}$ bond length of 1.53 $\AA$ of ethane, and much longer than the typical bond length $(1.42 \AA)$ of $\mathrm{sp}^{2}$ carbon. As shown in Figs. $1 \mathrm{~b}$ and 1c, the basic graphane structure is well retained with slight distortion of the hexagonal lattice in both P-substituted and $\mathrm{PH}_{2}$-grafted structures.
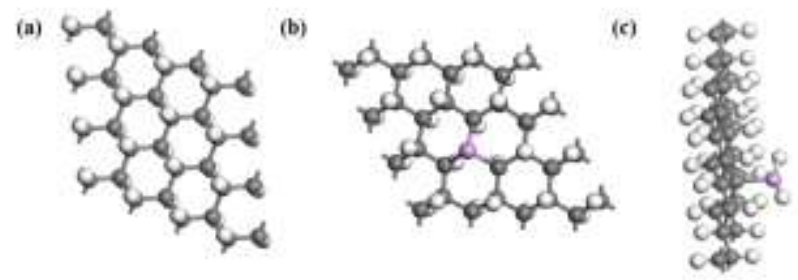

Fig. 1. Optimized graphane surfaces: (a) bare, (b) Psubstituted, and (c) $\mathrm{PH}_{2}$-grafted. Color code: gray, C; purple, $\mathrm{P}$; white, $\mathrm{H}$.

$\mathrm{CO}_{2}$ adsorption over P-substituted graphanes. To study the effects of P-site density on P-substituted graphane on $\mathrm{CO}_{2}$ adsorption, $\mathrm{CO}_{2}$ adsorption thermodynamics over a $4 \times$ 4 graphane unit cell surface with $0 \sim 2$ units of P-sites $(0$, 3.13 , and $6.27 \mathrm{wt} \%$ of P-site density) were studied. The optimized interaction configurations and adsorption energies are given in Fig. 2. For the substitution of $2 \mathrm{P}$-sites per graphane cell, three configurations of P-sites in meta-, para-, and ortho-positions were considered. Doping $\mathrm{P}$ atoms into a graphane unit cell strengthens the $\mathrm{CO}_{2}$ adsorption when compared to adsorption on an undoped surface (adsorption energy changes from -3.313 (undoped) to -4.895 (1-P) and 9.861 (2-P ortho-position) $\mathrm{kJ} / \mathrm{mol}$, respectively. The result suggests that higher P-site density gives more exothermic $\mathrm{CO}_{2}$ adsorption. With $2 \mathrm{P}$ atoms doped in the graphane unit cell, the $\mathrm{CO}_{2}$ adsorption energy varies with the placement of the $\mathrm{P}$ atoms, which increases in the order of ortho > para > meta. Regardless of the concentration of P-doped, all the adsorption of $\mathrm{CO}_{2}$ over P-substituted graphane is weak, similar to $\mathrm{CO}_{2}$ adsorption over $\mathrm{N}$-substituted graphane. ${ }^{[22]}$

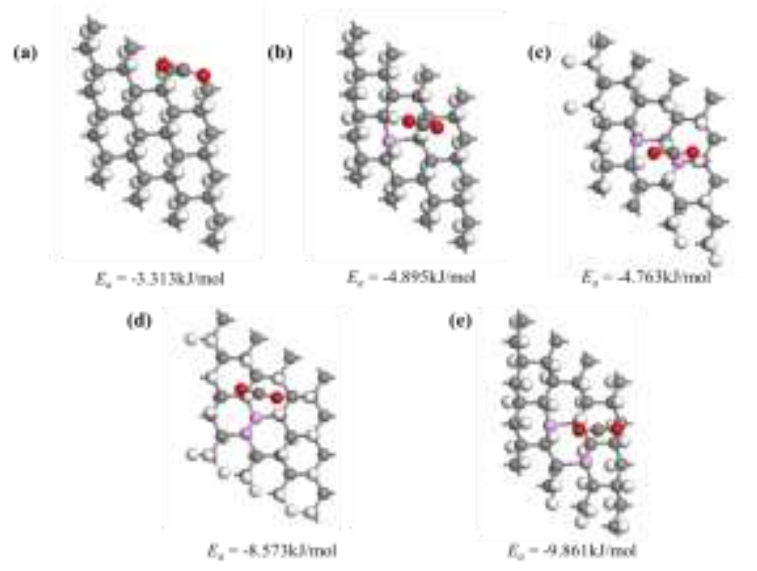

Fig. 2. Optimized interaction configurations and adsorption energies $\left(E_{a}\right.$, in $\left.\mathrm{kJ} / \mathrm{mol}\right)$ for $\mathrm{CO}_{2}$ adsorption over graphanes: (a) bare graphane; (b) single P-substituted graphane; (c) 2 Psubstitutions in meta-position; (d) 2 P-substitutions in paraposition; (e) $2 \mathrm{P}$-substitutions in ortho-position. Color code: gray, C; red, O; purple, $\mathrm{P}$; white, $\mathrm{H}$.

$\mathrm{CO}_{2}$ adsorption over $\mathrm{PH}_{2}$-grafted graphanes. Primary phosphino $\left(\mathrm{PH}_{2}-\right)$ grafted graphanes are expected to offer stronger basicity, ${ }^{[27]}$ leading to a stronger $\mathrm{CO}_{2}$ adsorption (an acidic molecule). This hypothesis was investigated via studying several modes of adsorption on these surfaces. One interaction configuration was $\mathrm{CO}_{2}$ physisorption, the other hypothesis configuration was the reaction of $\mathrm{PH}_{2-}$ and $\mathrm{CO}_{2}{ }^{[28]}$ Figs. 3a and $3 \mathrm{~b}$ show the proposed interaction configurations and adsorption energies. $\mathrm{CO}_{2}$ adsorbs weakly on graphane surface-functionalized with single grafted $\mathrm{PH}_{2}{ }^{-}$ sites, with an exothermic adsorption energy $-6.762 \mathrm{~kJ} / \mathrm{mol}$. The reaction of $\mathrm{PH}_{2}$ - and $\mathrm{CO}_{2}$ (Fig. 3b, $E_{a}=42.997 \mathrm{~kJ} / \mathrm{mol}$ ) is not favorable, comparing with physisoption over a single $\mathrm{PH}_{2}$-functionalized surface.

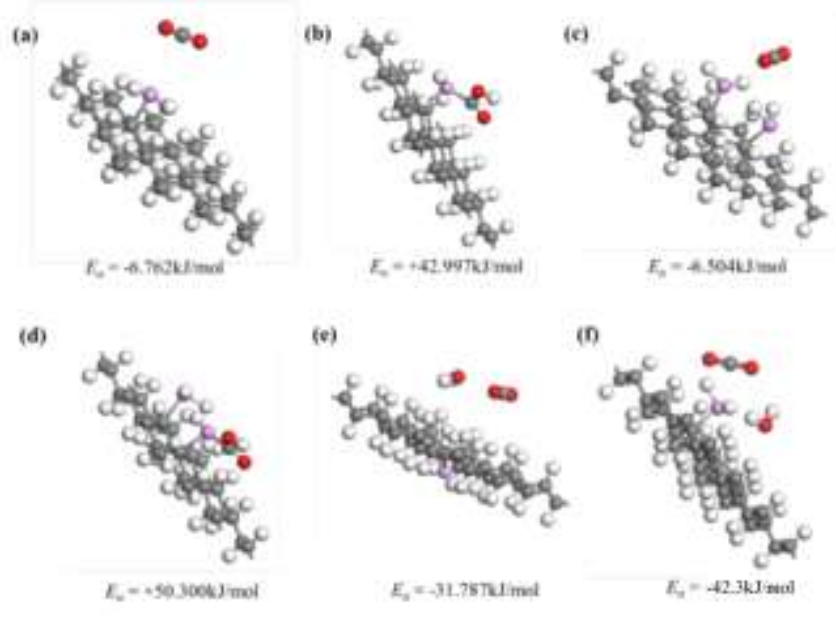

Fig. 3. Proposed interaction configurations and adsorption energies $\left(E_{a}\right.$, in $\left.\mathrm{kJ} / \mathrm{mol}\right)$ for $\mathrm{CO}_{2}$ adsorption on $\mathrm{P}$ functionalized graphanes: (a) $\mathrm{PH}_{2}$-grafted by physisorption; (b) $\mathrm{PH}_{2}-$ reaction with $\mathrm{CO}_{2} ;$ (c) $2 \mathrm{PH}_{2}$-grafted by physisorption; (d) one of the $2 \mathrm{PH}_{2}$ - reacting with $\mathrm{CO}_{2}$; (e) $\mathrm{P}$ substituted with $\mathrm{H}_{2} \mathrm{O}$; (f) $\mathrm{PH}_{2}$-grafted with water. Color code: gray, $\mathrm{C}$; red, $\mathrm{O}$; purple, $\mathrm{P}$; white, $\mathrm{H}$.

To further survey the effect of $-\mathrm{PH}_{2}$ functional group on $\mathrm{CO}_{2}$ adsorption, a second $-\mathrm{PH}_{2}$ functional group proximate to the $-\mathrm{PH}_{2}$ site is added. Also, two interaction configurations were studied: $\mathrm{CO}_{2}$ adsorption by (a) 
physisorption, (b) one of the $2 \mathrm{PH}_{2}$ - reaction with $\mathrm{CO}_{2}$, The optimized interaction configurations and adsorption energies are shown in Figs. 3c and 3d. Physisorption occurs with an adsorption energy of $-6.504 \mathrm{~kJ} / \mathrm{mol}$, while adsorption energies for $\mathrm{PH}_{2}$ - reaction with $\mathrm{CO}_{2}$ were also positive. The positive values of $E_{a}$ in two reaction configurations indicate that the structures are unstable relative to desorption. Bending the $\mathrm{CO}_{2}$ molecule or transferring a $\mathrm{H}$ atom to $\mathrm{CO}_{2}$ creates a local minimum energy structure, thus forming the instability. ${ }^{[22]}$ Compared to one $-\mathrm{PH}_{2}$ grafted, two proximate $-\mathrm{PH}_{2}$ functional groups on graphane hinder the $\mathrm{CO}_{2}$ adsorption, which is probably due to the geometrical restrictions. Overall, similar to P-substituted graphane, the density of phorphrus sites only slightly affects the $\mathrm{CO}_{2}$ adsorption energy. The adsorption of $\mathrm{CO}_{2}$ over $\mathrm{PH}_{2}$-grafted graphane is relatively weak, and $\mathrm{PH}_{2}-$ reaction with $\mathrm{CO}_{2}$ is not favorable. Therefore, neither P-substitution nor directly grafted $\mathrm{PH}_{2}$-groups on graphane provide favorable sites for $\mathrm{CO}_{2}$ adsorption.

\section{B. $\mathrm{CO}_{2}$ adsorption over P-Substituted and $\mathrm{PH}_{2}$-grafted graphanes in present of $\mathrm{H}_{2} \mathrm{O}$}

The content of water is $8-20 \%$ in power station offgas, ${ }^{[29]}$ so the effect of $\mathrm{H}_{2} \mathrm{O}$ on $\mathrm{CO}_{2}$ adsorption should be taken into consideration. Figs. $3 \mathrm{e}$ and $3 \mathrm{f}$ show the proposed interaction configuration and adsorption energies for $\mathrm{CO}_{2}$ adsorption over $\mathrm{P}$-substituted/directly grafted $\mathrm{PH}_{2}$-graphanes in the presence of $\mathrm{H}_{2} \mathrm{O}$. In Fig. 3e, the $\mathrm{H}_{2} \mathrm{O}$ molecule is weakly bonded to the P-site, and the measured $\mathrm{OH}-\mathrm{P}$ bond distance is $5.155 \AA$. The water molecule adsorbs $\mathrm{CO}_{2}$ strongly through a $\mathrm{C}-\mathrm{O}$ water electrostatic interaction, as reflected by the adsorption energy $E_{a}$ of $-31.787 \mathrm{~kJ} / \mathrm{mol}$. In Fig. 3f, $\mathrm{CO}_{2}$ adsorption to $\mathrm{PH}_{2}$-grafted graphane with $\mathrm{H}_{2} \mathrm{O}$, the $\mathrm{H}_{2} \mathrm{O}$ molecule is bonded to the $\mathrm{PH}_{2}$ group with the $\mathrm{OH}-\mathrm{P}$ bond distance $2.507 \AA$, with $E_{a}$ of $-42.3 \mathrm{~kJ} / \mathrm{mol}$. The presence of $\mathrm{H}_{2} \mathrm{O}$ strongly enhances $\mathrm{CO}_{2}$ adsorption over both $\mathrm{P}$-substituted and $\mathrm{PH}_{2}$-grafted graphanes. This result shows that as water is present in the flue gas ${ }^{[29]}$, and the process can be completed without the introduction of additional water, the extraction of $\mathrm{CO}_{2}$ from power station exhaust gas would be viable. However, the presence of water leads to an impure $\mathrm{CO}_{2}$ stream upon desorption, which needs to be further dried. ${ }^{[2]}$ Our results of $\mathrm{CO}_{2}$ adsorption over $\mathrm{P}$-substituted/directly grafted $\mathrm{PH}_{2}$-graphanes in the presence of $\mathrm{H}_{2} \mathrm{O}$ are also similar to $\mathrm{N}$-substituted/directly grafted $\mathrm{NH}_{2}$-graphanes ${ }^{[22]}$.

To better understand the change in the electronic structure of the gas adsorption system with the presence of water, the electron density for $\mathrm{CO}_{2}+\mathrm{H}_{2} \mathrm{O}+\mathrm{GAPH}_{2}$ adsorption system was analyzed. The results are shown in Fig. 4. It can be seen that there is no electron distribution among the $\mathrm{CO}_{2}$ molecule, the $\mathrm{H}_{2} \mathrm{O}$ molecule and the $\mathrm{GAPH}_{2}$ sheet. This indicates that the adsorption is physical. Also, the partial density of states (PDOS) of P-substituted/ $\mathrm{PH}_{2}$-grafted, $\mathrm{CO}_{2}$ on $\mathrm{GAP}+\mathrm{CO}_{2}+\mathrm{H}_{2} \mathrm{O}$ and $\mathrm{GAPH}_{2}+\mathrm{CO}_{2}+\mathrm{H}_{2} \mathrm{O}$ adsorption system were analyzed, respectively. Fig. 5a shows the PDOS for P-substituted configuration in $\mathrm{GAP}+\mathrm{CO}_{2}+\mathrm{H}_{2} \mathrm{O}$ adsorption system. There is no obvious change around the Fermi level. However, the $\mathrm{p}$ orbital has slight change after adsorption. This may be caused by the transfer between some electrons. Fig. 5b illustrates that the significant PDOS difference for $\mathrm{CO}_{2}$ in the adsorption system may also be caused by electrons transferring. Then, in Fig. 5c, the PDOS reveals the change of $\mathrm{PH}_{2}$-grafted in $\mathrm{GAPH}_{2}+\mathrm{CO}_{2}+\mathrm{H}_{2} \mathrm{O}$ adsorption system,. There exists mild shift of both $\mathrm{s}$ and $\mathrm{p}$ orbitals. The change of $\mathrm{CO}_{2}$ in $\mathrm{GAPH}_{2}+\mathrm{CO}_{2}+\mathrm{H}_{2} \mathrm{O}$ system is similar with $\mathrm{GAP}+\mathrm{CO}_{2}+\mathrm{H}_{2} \mathrm{O}$. The large charge transfer is expected to induce the change.



Fig. 4. The electron density for $\mathrm{CO}_{2}+\mathrm{H}_{2} \mathrm{O}+\mathrm{GAPH}_{2}$ adsorption system.

\section{Conclusions}

$\mathrm{CO}_{2}$ adsorption over various types of Psubstituted/grafted graphanes was studied using DFT. Psubstituted/grafted graphanes were constructed by substitution of lattice carbon or surface hydrogen with $\mathrm{P}$ functional groups. $\mathrm{CO}_{2}$ adsorbs weakly on a graphane surface functionalized with single substituted P- or grafted $\mathrm{PH}_{2}$-sites. The adsorption of $\mathrm{P}$-substituted/grafted graphanes can be strengthened with the presence of co-adsorbed $\mathrm{H}_{2} \mathrm{O}$. This theoretical work provides an atomic-level strategy in the design of functionalized graphane and carbon-based adsorbent materials for $\mathrm{CO}_{2}$ capture and storage. 
Proc. of the Third Intl. Conf. Advances in Bio-Informatics, Bio-Technology and Environmental Engineering- ABBE 2015 Copyright ( $)$ Institute of Research Engineers and Doctors, USA .All rights reserved.

ISBN: 978-1-63248-060-6 doi: 10.15224/ 978-1-63248-060-6-08
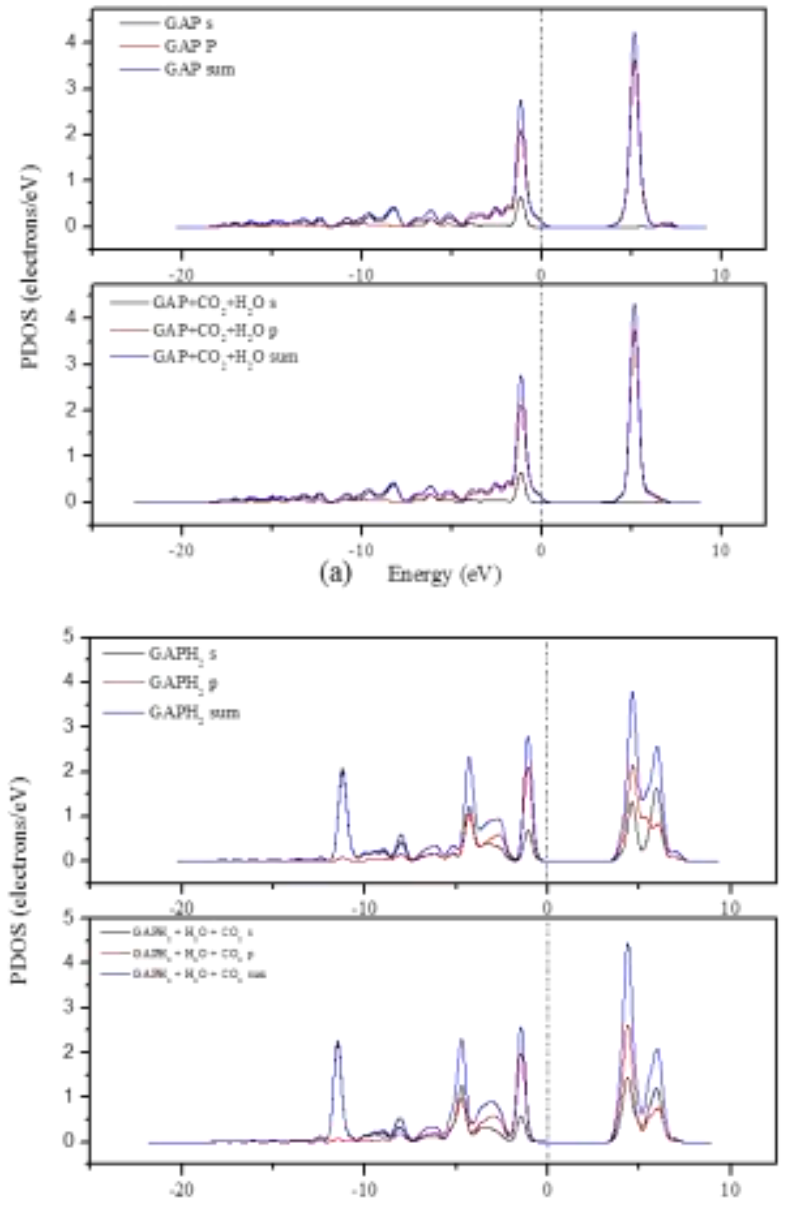

(c) Energy (eV)
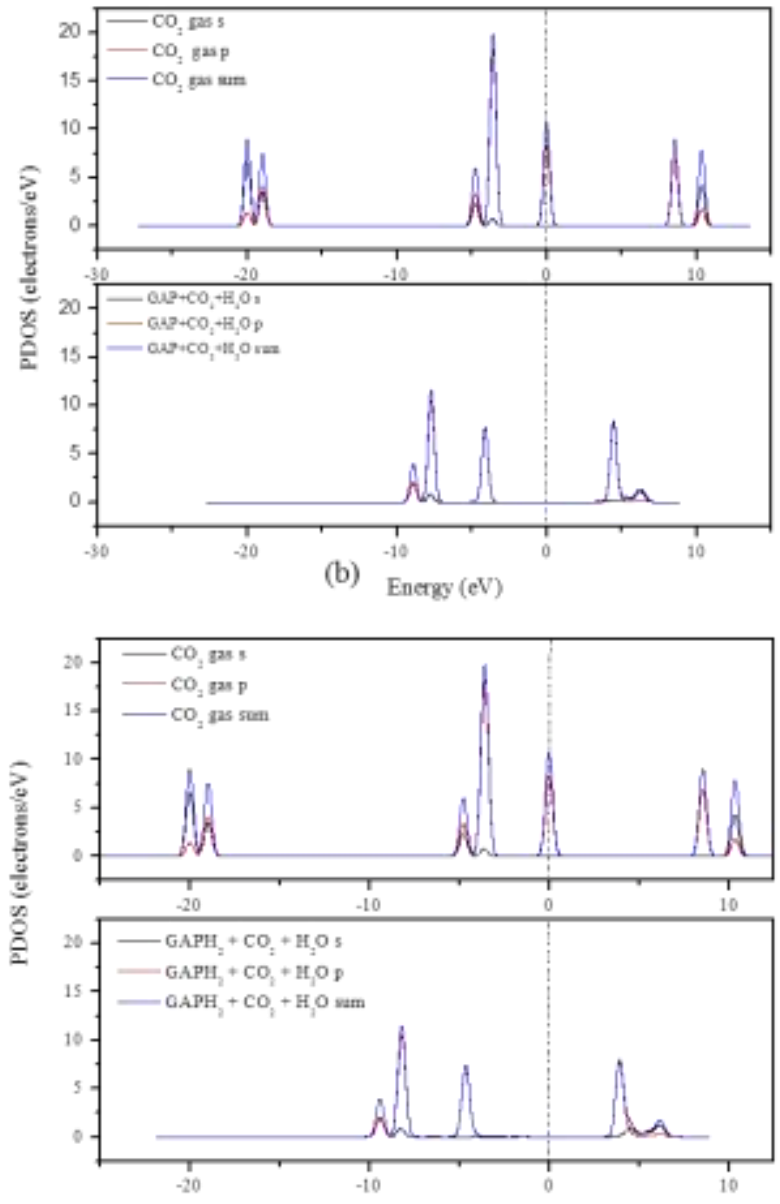

(d) Energy (eV)

Fig. 5. Partial density of state (PDOS) for $\mathrm{GAP}+\mathrm{CO}_{2}+\mathrm{H}_{2} \mathrm{O}$ and $\mathrm{GAPH}_{2}+\mathrm{CO}_{2}+\mathrm{H}_{2} \mathrm{O}$ systems (a) $\mathrm{PDOS}$ of $\mathrm{P}$ in $\mathrm{GAP}+\mathrm{CO}+\mathrm{H}_{2} \mathrm{O}$; (b) PDOS of $\mathrm{CO}_{2}$ in $\mathrm{CO}_{2}+\mathrm{H}_{2} \mathrm{O}+\mathrm{GAPH}_{2}$; (c) $\mathrm{PDOS}$ of $\mathrm{PH}_{2}$ in $\mathrm{GAPH}_{2}+\mathrm{CO}_{2}+\mathrm{H}_{2} \mathrm{O}$; (d) $\mathrm{PDOS}$ of $\mathrm{CO}_{2}$ in $\mathrm{GAPH}_{2}+\mathrm{CO}_{2}+\mathrm{H}_{2} \mathrm{O}$.

\section{References}

[1] R. A. Feely, S. C. Doney and S. R. Cooley, "Ocean Acidification: Present Conditions and Future Changes in a High- $\mathrm{CO}_{2}$ World," Oceanography, 2009, 22, pp. 36-47.

[2] K. Sumida, D. L. Rogow, J. A. Mason, T. M. McDonald, E. D. Bloch, Z.R. Herm, T.-H. Bae and J. R. Long, "Carbon Dioxide Capture in Metal-Organic Frameworks," Chem. Rev., 2012, 112, pp. 724-781.

[3] C. M. White, B. R. Strazisar, E. J. Granite, J. S. Hoffman and H. W. Pennline, "Separation and Capture of $\mathrm{CO} 2$ from Large Stationary Sources and Sequestration in Geological Formations - Coalbeds and Deep Saline Aquifers," Journal of the Air \& Waste Management Association, 2003, 6, pp. 645-715.

[4] Y. Zou, V. Mata and A. E. Rodrigues, "Adsorption of carbon dioxide at high temperature-a review," Separation and Purification Technology, 2002, 2, pp.195-205.

[5] J. J. Zhao, A. Buldum, J. Han and J. P. Lu, "Gas molecule adsorption in carbon nanotubes and nanotube bundles," Nonotechnology, 2002, 13, pp. 195.

[6] D. Mantzalis, N. Asproulis and D. Drikakis, "Filtering carbon dioxide through carbon nanotubes," Chem. Phys. Lett., 2011,506, pp. 81-85.

[7] W. J. Wang, X. Peng and D. P. Cao, "Capture of Trace Sulfur Gases from Binary Mixtures by Single-Walled Carbon Nanotube Arrays: A Molecular Simulation Study,” Environ. Sci. Technol., 2011, 45, pp. 4832-4838.
[8] J. J. Zhao, A. Buldum, J. Han and J. P. Lu, "Quantum transport properties of ultrathin silver nanowires," Nanotechnology, 2002, 13, pp. 195-200.

[9] E. Di Biase and L. Sarkisov, "Systematic development of predictive molecular models of high surface area activated carbons for adsorption applications," Carbon, 2013, 64, pp. 262-280.

[10] D. C. Wu, F. Xu, B. Sun, R. W. Fu, H. K. He and K. Matyjaszewski, "Design and Preparation of Porous Polymers," Chem. Rev., 2012, 112, pp. 3959-4015.

[11] H. S. Choi and M. P. Suh, "Highly Selective $\mathrm{CO}_{2}$ Capture in Flexible 3D Coordination Polymer Networks," Angew. Chem. Int. Ed., 2009, 48, pp. 6865-6869.

[12] X. Feng, X. S. Ding and D. L. Jiang, "Covalent organic frameworks," Chem. Soc. Rev., 2012, 41, pp. 6010-6022.

[13] R. Babarao and J. W. Jiang, "Exceptionally high $\mathrm{CO}_{2}$ storage in covalent-organic frameworks: Atomistic simulation study," Energy Environ. Sci., 2008, 1, pp. 139-143.

[14] K. Sumida, D. L. Rogow, J. A. Mason, T. M. McDonald, E. D. Bloch, Z.R. Herm, T.-H. Bae and J. R. Long, "Carbon dioxide capture in metal-organic frameworks," Chem. Rev., 2012, 112, pp. 724-781.

[15] F. Chang, J. Zhou, P. Chen, Y. L. Chen, H. H. Jia, S. M. I. Saad, Y. Gao,X. Cao and T. Zheng, "Cyclic $\mathrm{CO}_{2}$ capture of carbide slag modified by pyroligneous acid in calcium looping cycles," Asia-Pac. J. Chem. Eng., 2013, 8, pp. 618-626.

[16] M. X. Shan, Q. Z. Xue, N. N. Jing, C. C. Ling, T. Zhang, Z. F. Yan and J. T. Zheng, "Influence of chemical functionalization on the $\mathrm{CO}_{2} / \mathrm{N}_{2}$ separation performance of porous graphene membranes," Nanoscale, 2012, 4, pp. 5477-5482. 
[17] D. Smykowski, B. Szyja and J. Szczygieł, "GCMC simulations of $\mathrm{CO}_{2}$ adsorption on zeolite-supported Ir 4 clusters," J. Mol. Graph. Model, 2014, 50, pp. 35-43.

[18] M. Palomino, A. Corma, F. Rey and S. Valencia, "New Insights on $\mathrm{CO}_{2}-$ Methane Separation Using LTA Zeolites with Different Si/Al Ratios and a First Comparison with MOFs," Langmuir, 2010, 26, pp. 1910-1917.

[19] A. Savchienko, “Transforming Graphene," Science, 2009, 323, pp. 589-590.

[20] D. C. Elias, R. R. Nair, T. M. G. Mohiuddin, S. V. Morozov, P. Blake, M. P. Halsall, A. C. Ferrari, D. W. Boukhvalov, M. I. Katsnelson, A. K. Geim and K. S. Novoselov, "Control of Graphene's Properties by Reversible Hydrogenation: Evidence for Graphane,” Science, 2009, 323, pp. 610-613.

[21] J. O. Sofo, A. S. Chaudhari and G. D. Barber, "Graphane: a twodimensional hydrocarbon," Phys. Rev. B., 2007, 75, pp. $1534011-1534014$

[22] J. Xiao, S. Sitamraju and M. J. Janik, " $\mathrm{CO}_{2}$ Adsorption Thermodynamics over N-Substituted/Grafted Graphanes: A DFT Study," Langmuir, 2014, 30, pp. 1837-1844
[23] J. O. Sofo, A. M. Suarez, G. Usaj, P. S. Cornaglia, A. D. HernandezNieves and C. A. Balseiro, "Electrical control of the chemical bonding of fluorine on graphene,” Phys. Rev. B., 2011, 83, pp. 81411-81414.

[24] J. Dai, J. Yuan and P. Giannozzi, "Gas adsorption on graphene doped with B, N, Al, and S: A theoretical study," Appl. Phys. Lett., 2009, 95, pp. 232105.

[25] G. Savini, "Doped graphane: a prototype high-Tc electron-phonon superconductor," Phys. Rev. Lett. 105., 2010, arXiv:1002.0653v1.

[26] H. J. Monkhorst and J. D. Pack, “On Special Points for Brillouin Zone Integrations,” Phys. Rev. B., 1976, 13, pp. 5188-5192.

[27] W. A. Henderson and C. A. Streuli, "The Basicity of Phosphines," J. Am. Chem. Soc., 1960, 82 (22), pp.5791-5794.

[28] M. A. Carroll and A. B. Holmes, "Palladium-catalysed carbon-carbon bond formation in supercritical carbon dioxide," Chem. Commun., 1998, pp. 1395-1396.

[29] W. L. Wang, X. X. Wang, C. S. Song, X. L. Wei, J. Ding and J. Xiao, "Sulfuric Acid Modified Bentonite as the Support of Tetraethylenepentamine for $\mathrm{CO}_{2}$ Capture," Energy Fuels 2013, 27, pp. 1538-46. 